\title{
Conflitos em áreas de preservação permanente na bacia hidrográfica do Rio Pitimbu-RN: proposta de um indicador institucional de sustentabilidade
}

\author{
Conflicts in permanent preservative areas in the hydrographic river of the Pitimbu-Rn River: \\ proposal of an institutional sustainability indicator
}

\author{
Vinicius Meressiev Melo de Oliveira ${ }^{1}$ \\ Leci Martins Menezes Reis ${ }^{2}$
}

\begin{abstract}
Resumo
O objetivo deste estudo foi definir um indicador institucional de sustentabilidade, denominado de taxa de conflito em APP, mediante a correlação de conflitos entre as áreas de preservação permanente e de cobertura do solo, na bacia hidrográfica do Pitimbu - RN, em 2000 e em 2015. A coleta de dados foi realizada por meio de utilização de um sistema de informação geográfica (SIG). Primeiramente, os limites da bacia, assim como a sua rede de drenagem e reservatórios d'água, foram devidamente delimitados. Com esse procedimento realizado, foram geradas as áreas de APP de acordo com a legislação vigente. A partir de técnicas de processamento digital de imagem, produto de sensoriamento remoto orbital, as classes de uso do solo foram delimitadas. Dessa forma, foi realizado o cruzamento entre as áreas de APP e as classes de uso do solo para cada ano pesquisado, permitindo a identificação das áreas de conflito. Como resultado, destaca-se que no ano de 2000 houve um conflito potencialmente crítico de $35,4 \%$, e no ano de 2015 foi constatada uma piora, com conflito crítico de 42,52\%. Desse modo, a partir dos resultados apresentados, conclui-se que as áreas de APP da bacia hidrográfica do Rio Pitimbu - RN, no período pesquisado, se encontram em constante processo de degradação. Vale destacar também que, a partir da metodologia utilizada, a proposta do indicador mencionado é viável, e deve ser integrada a outros indicadores de diversas dimensões, ambiental, social, econômica e institucional, para se avaliar a sustentabilidade da bacia hidrográfica do Pitimbu - RN.
\end{abstract}

Palavras-chave: Bacia do Rio Pitimbu - RN. Conflito. Áreas de preservação permanente.

\begin{abstract}
The objective of this study was to define an institutional sustainability indicator, called the conflict rate in APP, through the correlation of conflicts between the permanent preservation and land cover areas, in the Pitimbu-RN basin, in 2000 and 2015. The data was collected using a geographic information system (SIG). First, the hydrographic basis limits, its drainage system and water reservoir were delimited. After that, the app areas were generated according to the actual legislation. From image digital processing technics, came from remote orbital censoring, the ground classes of usability were delimited. Hence, it was performed the match between the APP areas and the ground classes of usability for each year analysed, allowing the identification of the conflict areas. As a result, the year of 2000 can be highlighted, as there was a potentially critical conflict of $35.4 \%$, and in the year of 2015 it was even worse, with a critical conflict of $42.53 \%$. Therefore, as can be seen in the results, the areas of APP of the Pitimbu River's Hidrographic Basis in this period, are in constant process of degradation. It can also be highlighted that, using this methodology, the proposal of the indicator is

\footnotetext{
${ }^{1}$ Mestre em Ciências Ambientais pelo Instituto Federal de Educação Ciência e Tecnologia do Rio Grande do Norte (IFRN). E-mail: vinicius_oliveira_@hotmail.com.

${ }^{2}$ Professora Doutora da Diretoria de Recursos Naturais do Instituto Federal de Educação Ciência e Tecnologia do Rio Grande do Norte - IFRN. E-mail: leci.reis@ifrn.edu.br.
} 
viable and has to be integrated to other indicators of a range of dimensions, environmental, social, economic and institutional, in order to evaluate the Pitimbu River's Hidrographic Basis.

Keywords: Pitimbu river's hidrographic basis. Conflict. Permanent preservation areas.

\section{Introdução}

As áreas de preservação permanente (APPs) são previstas na Lei n 12.651 , de 25 de maio de 2012, conhecida como novo código florestal. Estas podem ser definidas como uma faixa de proteção, com presença ou não de vegetação nativa, que tem a função ambiental de preservar os recursos hídricos, a paisagem, estabilidade geológica, biodiversidade, fauna, flora, o solo, e garantir a qualidade de vida da sociedade, por meio da manutenção da quantidade e qualidade dos recursos hídricos disponíveis para os diversos usos (BRASIL, 2012).

Porém, mesmo previstas em lei, as áreas de preservação permanente vêm sendo gradativamente degradadas, ao longo das últimas décadas, pelas atividades antrópicas no Brasil (SCHÃFFER et al., 2011). Com isso, vários estudiosos estão se debruçando em compreender as causas e os efeitos desse problema, a partir de diferentes visões e escalas de análise.

Para tanto, pode-se afirmar que o recorte territorial ideal para análise e intervenção é a bacia hidrográfica. Esta é prevista na Política Nacional de Recursos Hídricos, Lei nº 9.433, de 8 de janeiro de 1997, como a unidade ideal de planejamento para a gestão das águas, pelo fato de ser um local de convergência entre o meio físico, biótico e antrópico (YASSUDA, 1993; GUERRA, 2011).

Porém, o que se percebe atualmente, dentro das bacias hidrográficas brasileiras, em grande parte, é o descompromisso quanto à manutenção das áreas de preservação permanente, por parte da sociedade e suas atividades, e do poder público, como agente fiscalizador. Podem-se destacar, ainda, as principais atividades que causam influência direta na degradação das áreas de preservação permanente, dentro de bacias hidrográficas: a agricultura e a expansão urbana (TUCCI; MENDES, 2006).

Por esse viés, mesmo desempenhando um importante papel na estabilidade ambiental, no desenvolvimento social e econômico, e com relação ao abastecimento de água dos municípios de Natal, Parnamirim e Macaíba, a bacia hidrográfica do Rio Pitimbu, no Rio Grande do Norte (RN), vem sendo degradada, ao longo das últimas décadas, mediante a intensa supressão vegetal para viabilizar atividades agrícolas e de consolidação urbana. Consequentemente, ocorre o conflito em áreas de preservação permanente, desde a nascente, ao longo das margens do rio principal e de afluentes, e no entorno dos lagos e lagoas locais (BORGES, 2002). 
Nessa perspectiva, o conceito de conflito socioambiental está diretamente relacionado à exploração e à reposição dos recursos naturais, diante de disputas que envolvem diversos atores sociais com ideologias divergentes no que diz respeito à natureza e a sua preservação (BRITO et al., 2011).

Sendo assim, o conflito causado pelas atividades antrópicas nas áreas de preservação permanente, na bacia hidrográfica do Rio Pitimbu, pode estar contribuindo para o seu desenvolvimento insustentável, uma vez que a degradação das áreas de preservação permanente é contraditória com relação ao conceito de sustentabilidade, sendo essa definida como a capacidade de satisfazer a necessidade do presente sem comprometer a capacidade das gerações futuras de atenderem suas próprias necessidades (SASAHARA, 2009).

Porém, para mensurar a sustentabilidade local, é preciso definir e aplicar indicadores, elencados por fazerem parte de um sistema de informações sobre o desenvolvimento sustentável da interação homem-natureza, considerando as dimensões ambiental, social, econômica e institucional (BELLEN, 2005).

Embora existam inúmeras pesquisas que exploram os problemas socioambientais nas APPs da bacia hidrográfica do Rio Pitimbu, como a de Costa (1995), Borges (2002) e Barbosa (2006), não foram identificados estudos com maior profundidade sobre indicadores institucionais de sustentabilidade com foco na proteção das áreas de preservação permanente. É importante também destacar que a manutenção das áreas de preservação permanente, além de prevista em legislação, constitui-se em um dever do poder público, exequível por meio de ações de controle de órgãos federais, estaduais e municipais que fiscalizam o cumprimento da legislação para a preservação ambiental.

Diante de tal problemática, a pesquisa foi norteada pela respectiva questão central: qual indicador institucional de sustentabilidade pode ser proposto para a detecção especial de conflitos gerados pelo uso e ocupação do solo nas áreas de preservação permanente na bacia hidrográfica do Rio Pitimbu, nos anos de 2000 e de 2015 comparativamente?

A partir desse questionamento, o objetivo geral deste estudo foi propor um indicador institucional de sustentabilidade, com base na estimativa de áreas de conflitos existentes entre a cobertura do solo e as áreas de preservação permanente na bacia hidrográfica do Rio Pitimbu, nos anos de 2000 e 2015, comparativamente.

Levando em consideração que as áreas de preservação permanente desempenham grande importância em um contexto ambiental, social, econômico e institucional de uma bacia hidrográfica, a execução da presente pesquisa justifica-se pelo fato de contribuir para a proposição de um indicador institucional de sustentabilidade, que permita avaliar e também subsidiar a tomada de decisões 
necessárias ao alcance do desenvolvimento local integrado e sustentável em uma bacia hidrográfica, no que tange à integridade da sua área de preservação permanente.

Concomitantemente, esse indicador permitirá aos tomadores de decisão avaliar os locais de conflito e os seus agentes responsáveis, de modo que poderá direcionar ações no sentido da preservação dessas áreas por meio de medidas institucionais de controle. Para o meio acadêmico, essa pesquisa se torna interessante pelo fato da abordagem temática ser inédita na bacia hidrográfica do Rio Pitimbu, assim como a metodologia empregada e descrita poderá ser utilizada para outras áreas de estudo.

Para tanto, a pesquisa está estruturada da seguinte forma: contextualização teórica, na qual são discutidos os conceitos essenciais para a compreensão do estudo; metodologia, na qual a área é caracterizada e é descrito o tipo de pesquisa e o procedimento metodológico adotado para atingir o objetivo geral; análise e discussão dos resultados, nas quais são apresentados e interpretados os dados coletados; e as conclusões da pesquisa.

\section{Indicador institucional de sustentabilidade em uma perspectiva sobre conflitos em áreas de preservação permanente}

Nas seções a seguir, serão apresentados e discutidos os conceitos centrais que nortearam a pesquisa aqui desenvolvida, tais como: conflito em áreas de preservação permanente em bacias hidrográficas e indicador institucional de sustentabilidade.

\section{Conflito em áreas de preservação permanente em bacias hidrográficas}

Na maioria dos dicionários brasileiros, a palavra conflito é relacionada à ideia de oposição de interesses, disputa, desentendimento e desordem (KURY, 2002). Porém, em termos teóricos, a discussão sobre o conceito de conflito, sobre sustentabilidade de recursos naturais, foi consolidada entre as décadas de 1960 e 1980, a partir da criação do Clube de Roma em 1968 e da realização da Conferência de Estocolmo em 1972, culminando na introdução dos estudos sobre conflitos socioambientais na agenda mundial. Nessa perspectiva, o conceito de conflito socioambiental está diretamente relacionado à exploração e à reposição dos recursos naturais, diante de disputas que envolvem diversos atores sociais com ideologias divergentes no que diz respeito à natureza e a sua preservação (BRITO et al., 2011).

Corroborando com esse pensar, o autor Libiszewski (1992) compreende que os conflitos socioambientais têm suas raízes atreladas à escassez de um recurso natural, marcado por uma 
perturbação na sua dinâmica natural de regeneração provocada pela ação humana, causando desequilíbrio ambiental. Dentro desse ponto de vista, também se torna interessante afirmar que, além da escassez de um dado recurso natural, os conflitos socioambientais estão diretamente relacionados à disputa destes, causando um desequilíbrio entre a sua oferta e procura, culminando no seu uso insustentável (TUNNER, 2004).

De uma forma mais complexa, baseado na ideia de sociologia da ação, em que os atores sociais são os responsáveis pelas intervenções, o autor Ribeiro (1995) compreende o meio ambiente como setor que integra o espaço público, ou seja, como um bem público. Desse modo, é nesse espaço que os atores sociais entram em conflito com o meio ambiente, a partir da disputa de interesses, para obter vantagens de ordem socioeconômica, causando impactos negativos relacionados à exploração inconsequente dos recursos naturais. O mesmo autor entende que o desenrolar desses conflitos é diretamente influenciado pelas políticas públicas implementadas no local, pela participação dos atores envolvidos, assim como pela capilarização na sociedade do que se entende por conservação.

Nas bacias hidrográficas ocorrem, frequentemente, conflitos entre a cobertura do solo e as áreas de preservação permanente. Além de estarem em desacordo com a Lei no 12.651, de 25 de maio de 2012 (BRASIL, 2012), esses conflitos causam diversas consequências negativas ao meio ambiente e à qualidade de vida da sociedade, tais como: erosão, contaminação da água, assoreamento e desvios dos rios, empobrecimento do solo, e influência na qualidade e disponibilidade de água para consumo (VAZ; ORLANDO, 2012).

Concomitantemente, esses problemas repercutem diretamente na economia, pois quanto maior a ocorrência, maiores os recursos que devem ser destinados à recuperação de áreas, captação e tratamento de água. Por sua vez, a ocorrência desses problemas está diretamente relacionada à capacidade do poder público, por meio das suas diversas instituições, em evitá-los, por meio de mecanismos de fiscalização e controle. Com isso, entende-se que os impactos negativos ao meio ambiente, devido à ocorrência de conflitos em áreas de preservação permanente de bacias hidrográficas, geram desequilíbrios nas dimensões social, econômica, ambiental e institucional, contribuindo para um desenvolvimento insustentável.

\section{Indicador institucional de sustentabilidade}

Os indicadores de sustentabilidade surgiram a partir da necessidade de operacionalizar o conceito de desenvolvimento sustentável. Assim como um médico que, para diagnosticar uma enfermidade ou para poder caracterizar o nível de saúde de determinado indivíduo, necessita de informações sobre a realidade de seu paciente, para se determinar a sustentabilidade um pesquisador 
precisa de informações que representem a realidade de dado local nas dimensões ambiental, social, econômica e institucional (SEPÚLVEDA, 2008).

Com isso, indicadores são variáveis selecionadas e quantificadas que permitem definir situações que não seriam tão facilmente identificadas por outro meio. Bons indicadores devem ter como função a representação da realidade, assim como conter informações relevantes sobre o desempenho de um sistema, seu futuro, com comunicação objetiva e de fácil interpretação (SARADÓN, 2013).

À vista disso, a Agenda 21, principal documento produto da Rio-92, em seu Capítulo 40, recomenda a utilização de indicadores de desenvolvimento sustentável por parte das nações com foco no planejamento, os quais podem ser quantitativos e/ou qualitativos, assumindo um valor em um tempo e espaço específicos, com a finalidade de transmitir informações e para subsidiar a tomada de decisão. Assim, os indicadores expõem uma linguagem que possibilita a compreensão da realidade da sustentabilidade de um dado território, sendo essencial para identificação de problemas e formulação de políticas públicas (GUIMARÃES; FEICHAS, 2009).

Recentemente, indicadores da dimensão institucional vêm sendo contemplados em trabalhos de mensuração da sustentabilidade de territórios. Esses indicadores institucionais começam a ganhar espaço no meio acadêmico a partir do ano 2000 por meio do relatório Indicators of sustainable development: guidelines and methodologies, da Organização das Nações Unidas (ONU), resultado de inúmeras discussões e testes que vinham ocorrendo desde 1990 (MELO, 2013).

A utilização da dimensão institucional expressa um consenso entre os pesquisadores de que esta representa as ações políticas que influenciam diretamente no uso sustentável de recursos naturais. Sobre isso, o Instituto Brasileiro de Geografia e Estatística (BRASIL, 2012) destaca a importância de indicadores institucionais de sustentabilidade, pelo fato de representar o rumo político, predisposição e empenho exercidos por instituições governamentais, e pela sociedade, no sentido de atender aos pré-requisitos para um desenvolvimento sustentável.

\section{Metodologia}

Nas seções a seguir, foi caracterizada a área objeto de estudo, assim como é descrito o procedimento metodológico executado pela pesquisa. 


\section{Caracterização da área}

A bacia hidrográfica do Pitimbu, localizada no estado do Rio Grande do Norte, mais especificamente na mesorregião Leste Potiguar (Figura 01), apresenta área total de aproximadamente 12.397,7 ha, ocupando parte dos municípios de Natal, Macaíba e Parnamirim, ambos integrantes da Região Metropolitana de Natal (Tabela 01), e o seu acesso pode ser realizado por meio das rodovias federais BR-226, BR-304 e BR-101. A sua forma pode ser caracterizada como um polígono irregular, de modo que seu retângulo envolvente se encontra entre os paralelos $5^{\circ} 50^{\prime} 00^{\prime}$ e $5^{\circ} 57^{\prime} 53^{\prime}$ ' de latitude sul e os meridianos $35^{\circ} 11^{\prime}$ ' $08^{\prime}$ ' e $35^{\circ} 23^{\prime}$ '19', de longitude oeste.

Essa bacia litorânea pode ser caracterizada como endorréica, pois o rio principal não deságua no mar e apresenta a drenagem em forma dendrítica, por consequência da geomorfologia da área (CRISTOFOLETTI, 1974), fazendo parte de um conjunto de bacias que integram a bacia de drenagem do Pirangi, que tem o exultório no Oceano Atlântico, banhando os municípios de Nísia Floresta, São José do Mipibu e Vera Cruz, além dos já mencionados, ambos localizados no estado do Rio Grande do Norte (BORGES, 2002).

O principal rio da bacia hidrográfica do Pitimbu, de mesmo nome, tem aproximadamente $33 \mathrm{~km}$ de comprimento, sendo a sua nascente no município de Macaíba, na comunidade de Lagoa Seca, e seu exultório na Lagoa do Jiqui, no município de Parnamirim. Aproximadamente $13 \mathrm{~km}$ da sua extensão são caracterizados por área rural, predominantemente localizados no município de Macaíba, de modo que à medida que adentra nos municípios de Parnamirim e Natal, apresenta aglomerações urbanas e industriais nas suas margens (SENA, 2008).

O Rio Pitimbu desempenha grande importância estratégica para a zona rural do município de Macaíba e zona urbana dos municípios de Parnamirim e Natal, sendo responsável por cerca de 30\% do abastecimento de água do último município citado (OLIVEIRA, 2012). 


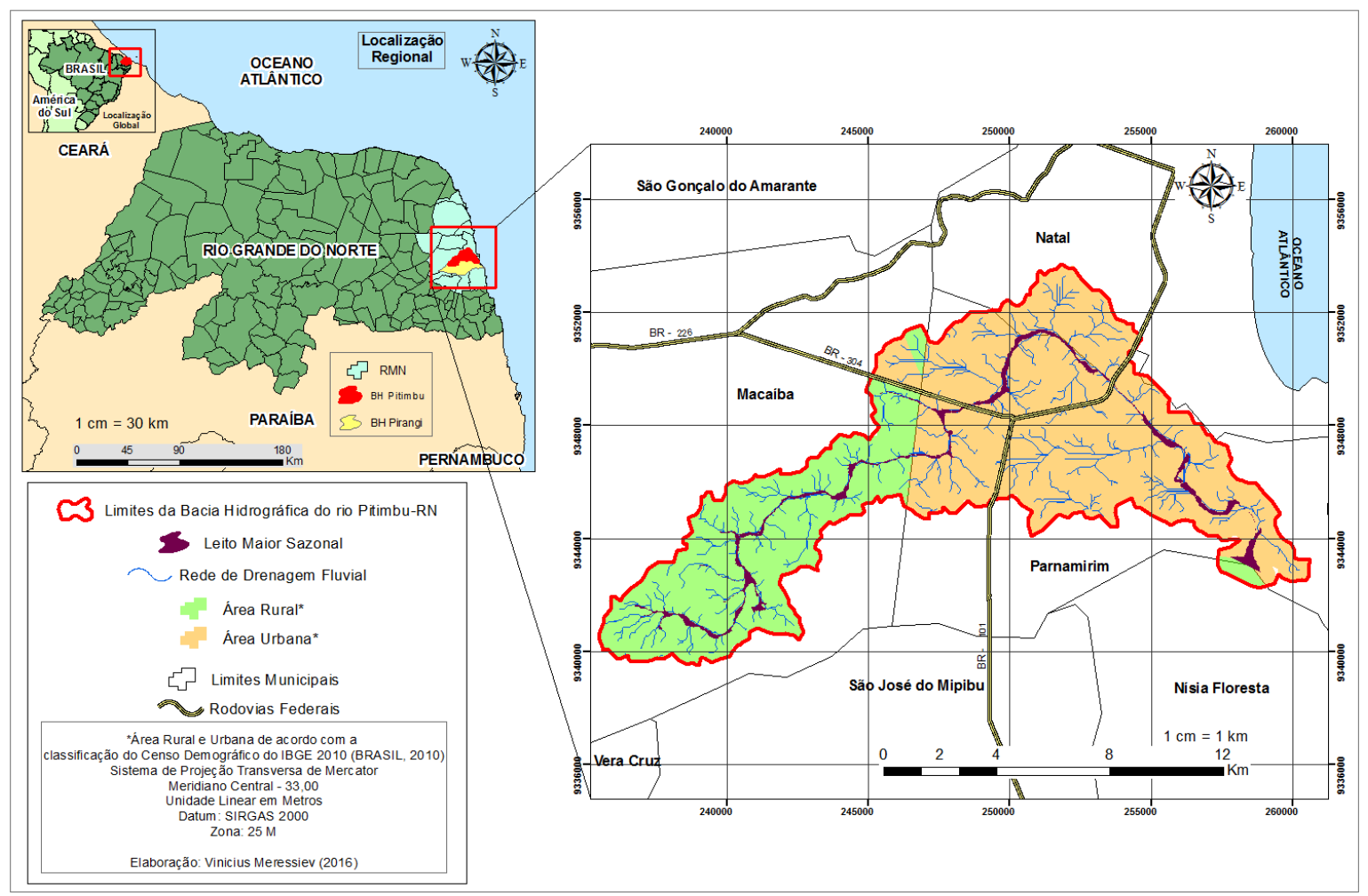

FIGURA 01 - LOCALIZAÇÃO GEOGRÁFICA DA BACIA HIDROGRÁFICA DO RIO PITIMBU, RIO GRANDE DO NORTE, BRASIL

FONTE: Os autores (2016).

TABELA 01 - ÁREA DA BACIA HIDROGRÁFICA DO PITIMBU, RIO GRANDE DO NORTE (BRASIL) POR MUNICÍPIO

\begin{tabular}{ccc}
\hline Município & Área (ha) & \% \\
\hline Macaíba & $4.718,41$ & 38,05 \\
\hline Natal & $1.001,34$ & 8,07 \\
\hline Parnamirim & $6.678,04$ & 53,86 \\
\hline Total & $12.397,79$ & 100 \\
\hline
\end{tabular}

FONTE: Os autores (2016).

\section{Procedimentos metodológicos}

Do ponto de vista da natureza da pesquisa, esta pode ser considerada como aplicada, podendo ser empregada de forma prática, com vistas à mitigação de problemas de conflito entre a cobertura do solo e as áreas de preservação permanente dentro da área objeto de estudo. Nesse sentido, primeiramente, foi realizada uma pesquisa exploratória, com o objetivo de levantar informações sobre o tema abordado, o que facilitou a contextualização e delimitação do problema de pesquisa, assim como a definição dos objetivos geral e específicos.

Com relação aos procedimentos técnicos, após a etapa anterior, foi realizada uma pesquisa bibliográfica, a partir de material já publicado, incluindo livros, publicações em periódicos e artigos 
científicos, dissertações e teses. Essa pesquisa bibliográfica nos proporcionou a construção do referencial teórico e o acesso aos dados gerados por pesquisas anteriores na mesma área de estudo.

Todas as técnicas de manipulação de dados geográficos e de elaboração das cartas foram realizadas no sistema de informação geográfica (SIG) ArcGis 10.2. Para a delimitação da bacia do Rio Pitimbu, foram utilizadas as folhas 05s36_e 06s36_, da missão topográfica radar shuttle (SRTM), do ano de 2000, a qual contém as informações de coordenadas (x e y) e de altitude (z).

Primeiramente, foi extraída a drenagem a partir do aplicativo hidrology, presente no SIG já citado, a partir das seguintes ações: preenchimento (correção) da imagem ( fill), definição da direção e da acumulação de fluxo da água (flow direction e flow acumulation). Após esses procedimentos, foi locado o exultório da bacia, para que seus limites fossem delimitados, por meio do procedimento whatershed.

Após a extração da drenagem e a delimitação dos limites da bacia do Pitimbu, foram separados os cursos d'água que estão passíveis de preservação permanente em suas margens, de acordo com o Art. $4^{\circ}$ da Lei $n^{\circ} 12.651$ (Novo Código Florestal): curso d'água natural perene e intermitente, excluídos os efêmeros.

Essa separação foi realizada por meio do aplicativo hidrology, função stream order (ordem do rio). Foram sobrepostas também a área da nascente do Rio Pitimbu e das lagoas localizadas na bacia, porque suas margens também são áreas de preservação permanente. Os arquivos vetoriais dessas feições foram disponibilizados pelo Instituto de Desenvolvimento e Meio Ambiente do RN (IDEMA).

Após a delimitação da rede de drenagem perene e intermitente, lagoas e nascente, o próximo passo foi definir as áreas de APP, de acordo com a Lei $\mathrm{n}^{\circ}$ 8.426, de 14 de novembro de 2003 (RIO GRANDE DO NORTE, 2003), que dispõe sobre a faixa de proteção ambiental do Rio Pitimbu, e a Lei $\mathrm{n}^{\circ}$ 12.651, de 25 de maio de 2012 (BRASIL, 2012), Novo Código Florestal. Nessas legislações, sempre foi dada a preferência aos itens mais restritivos, como forma de escolher os procedimentos corretos a serem adotados. Logo, foi adotado como parâmetro o leito maior sazonal (LMS) dos rios perenes e intermitentes, definido pela legislação estadual, sendo essa mais restritiva do que o Novo Código Florestal, que adota o leito regular.

O leito maior sazonal é definido pela resolução Conama $n^{\circ}$ 04, de 18 de setembro de 1985 (BRASIL, 1985), como a calha alargada ou maior de um rio, ocupada nos períodos anuais de cheia, ou seja, confunde-se com a área de várzea. A área de várzea é definida por Pereira e Witikoski (2012, p. 275) como o "lugar onde há ligação direta entre água e terra, em que numa época do ano o solo fica exposto, ou seja, seco e, noutra época, fica inundado". Para a delimitação do leito maior sazonal, 
foi utilizado arquivo vetorial do tipo shapefile disponibilizado pela Secretaria Estadual de Meio Ambiente e dos Recursos Hídricos do RN (Semarh).

Para as nascentes, lagoas e rios perenes e intermitentes, com o leito maior sazonal de até 200 $\mathrm{m}$ de largura, foi definida uma área de APP de $100 \mathrm{~m}$ a partir das suas bordas. Para os rios com o leito maior sazonal superior a $200 \mathrm{~m}$ de largura, foi adotada uma área de APP de $200 \mathrm{~m}$. Essas áreas foram delimitadas a partir do aplicativo analysis tools, seguido dos procedimentos proximity e buffer (Figura $02)$.

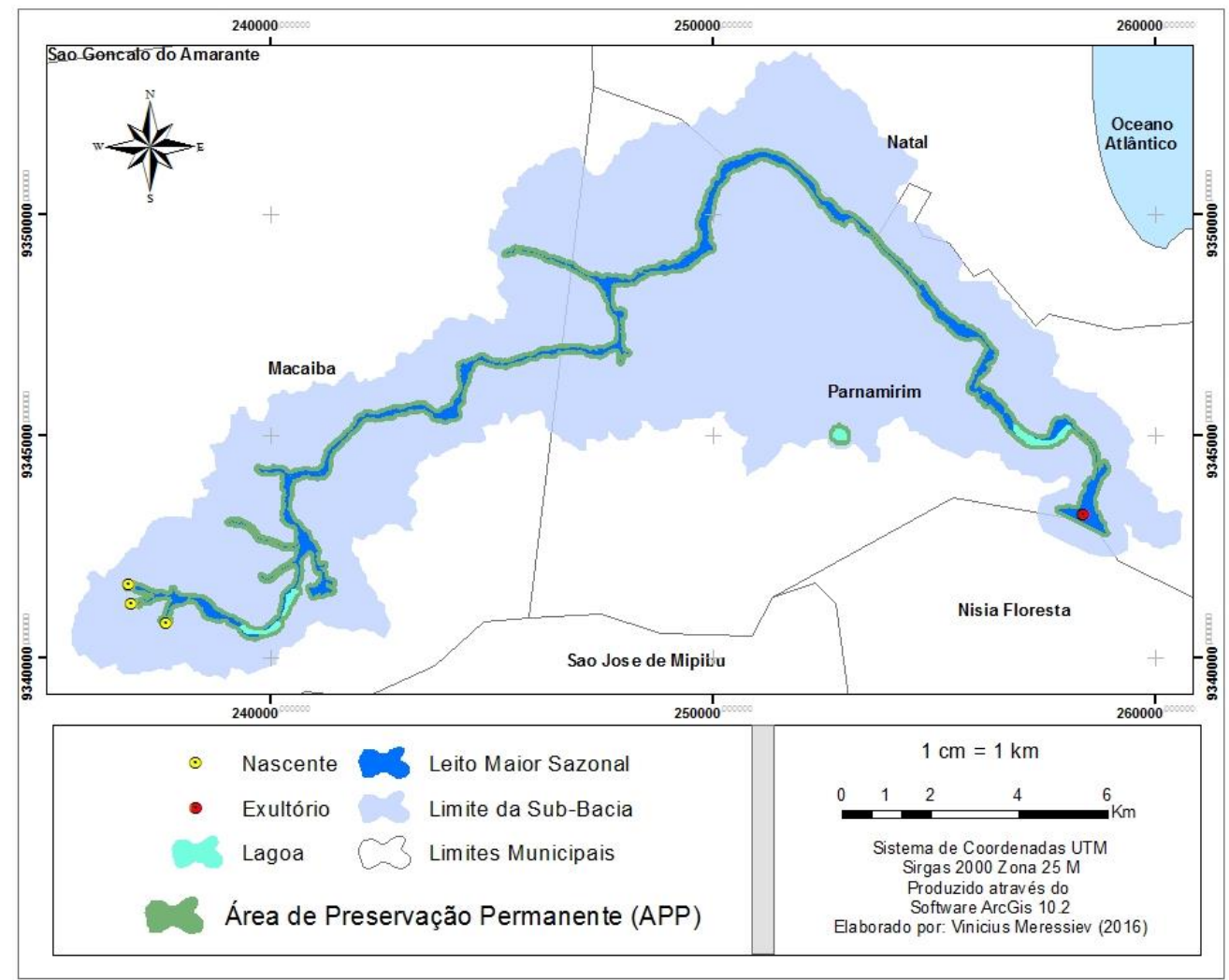

FIGURA 02 - ÁREAS DE PRESERVAÇÃO PERMANENTE DA BACIA HIDROGRÁFICA DO RIO PITIMBU, RIO GRANDE DO NORTE, BRASIL

FONTE: Os autores (2016).

Após a definição das áreas de preservação permanente, foram delimitados os tipos de cobertura do solo presentes na bacia. Essa delimitação seguiu uma adaptação do padrão proposto pelo Manual do Uso da Terra do IBGE (BRASIL, 2013), em que as seguintes classes foram identificadas: áreas antrópicas agrícolas, áreas antrópicas não agrícolas, áreas de vegetação e solo exposto (Quadro 01). A classe solo exposto, não prevista no manual, foi introduzida pelo fato dessas áreas produzirem influência na preservação dos recursos hídricos, de modo que quanto mais frequentes, maior será a probabilidade de processos de erosão/sedimentação e consequentemente assoreamento do rio. 
QUADRO 01 - CLASSES DE COBERTURA DO SOLO IDENTIFICADAS NA BACIA DO RIO PITIMBU, RIO GRANDE DO NORTE (BRASIL)

\begin{tabular}{|c|l|}
\hline \multicolumn{1}{|c|}{ Classes } & \multicolumn{1}{c|}{ Características } \\
\hline \multirow{2}{*}{ Áreas antrópicas agrícolas } & $\begin{array}{l}\text { Terra utilizada para a produção de alimentos, fibras e } \\
\text { commodities do agronegócio. Inclui todas as terras } \\
\text { cultivadas, caracterizadas pelo delineamento de áreas } \\
\text { cultivadas ou em descanso, podendo também } \\
\text { compreender áreas alagadas. Podem se constituir em } \\
\text { zonas agrícolas heterogêneas ou representar extensas }\end{array}$ \\
áreas de plantations. Encontram-se inseridas nesta \\
categoria as lavouras temporárias, lavouras \\
permanentes, pastagens plantadas, silvicultura e áreas \\
comprovadamente agrícolas cujo uso não foi \\
identificado no período do mapeamento (BRASIL, \\
2013).
\end{tabular}

FONTE: Os autores (2016).

Para definir as classes, foi realizada para cada ano uma classificação supervisionada por máxima verossimilhança (MAXVER) de imagem multiespectral Landsat 7, para o ano de 2000, e Landsat 8 para o ano de 2015, através de uma composição de bandas coloridas, vermelho, verde e azul (RGB), para melhor identificação das classes pretendidas (Figura 03). 


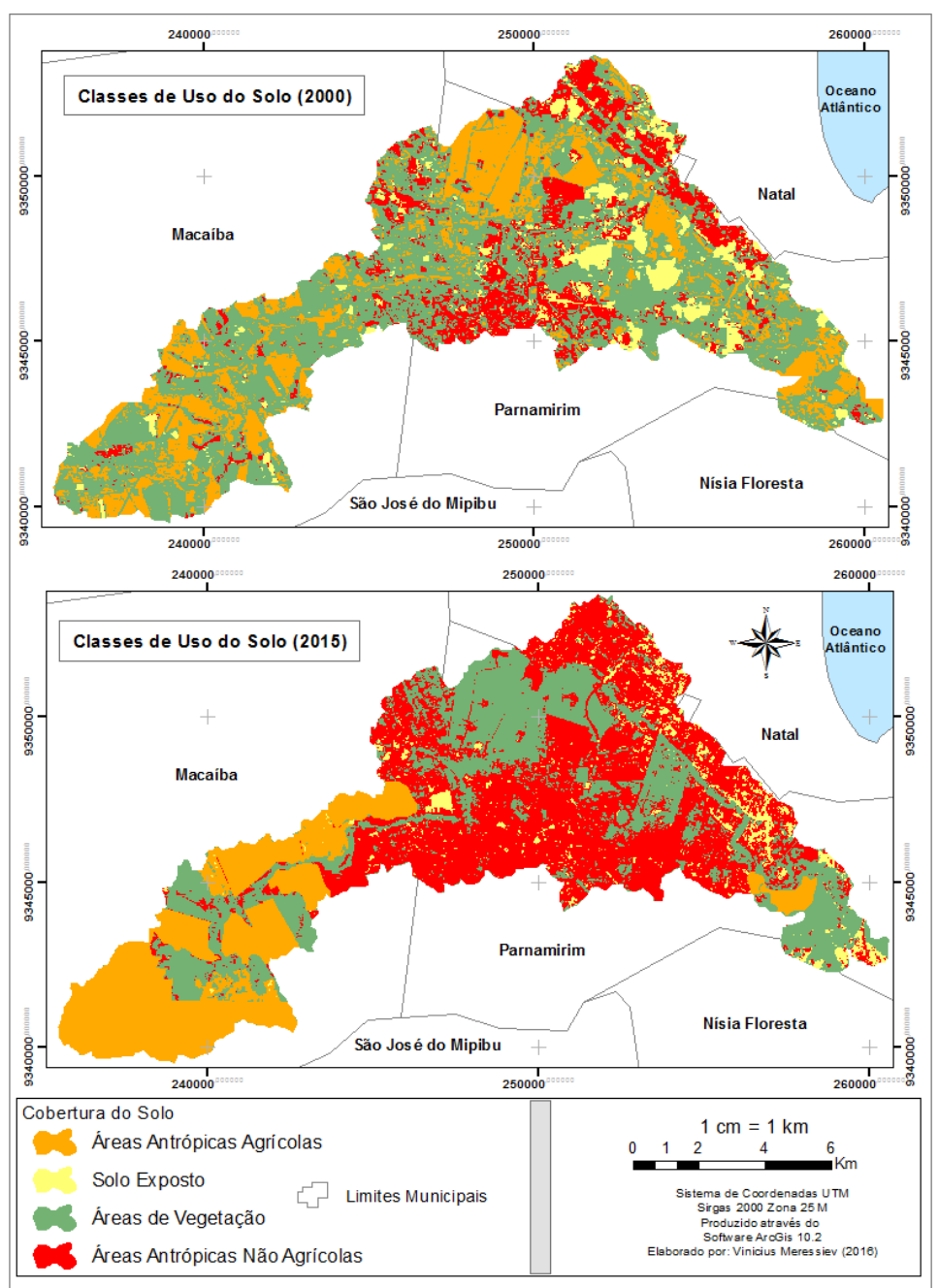

FIGURA 03 - CLASSES DE USO DO SOLO NA BACIA HIDROGRÁFICA DO RIO PITIMBU, RIO GRANDE DO NORTE (BRASIL), NOS ANOS DE 2000 E 2015

FONTE: Os autores (2016).

Com as áreas de preservação permanente e as classes de cobertura do solo devidamente delimitadas, foi possível realizar uma correlação espacial das áreas de conflitos entre esses dois produtos e definir sua distribuição geográfica calculando a sua área em hectares total e por classe, para cada ano pesquisado. Vale salientar que nessa correlação espacial não foram contempladas as áreas de vegetação natural, por não se tratar de um conflito, visto que as áreas de preservação permanente são formadas por essa classe. Os polígonos de conflito foram separados por meio do aplicativo analysis tools, seguindo os procedimentos extract e clip. Para o cálculo das áreas de cada classe, assim como das áreas de conflito, foi utilizado o aplicativo calculate geometry (Figura 04). 


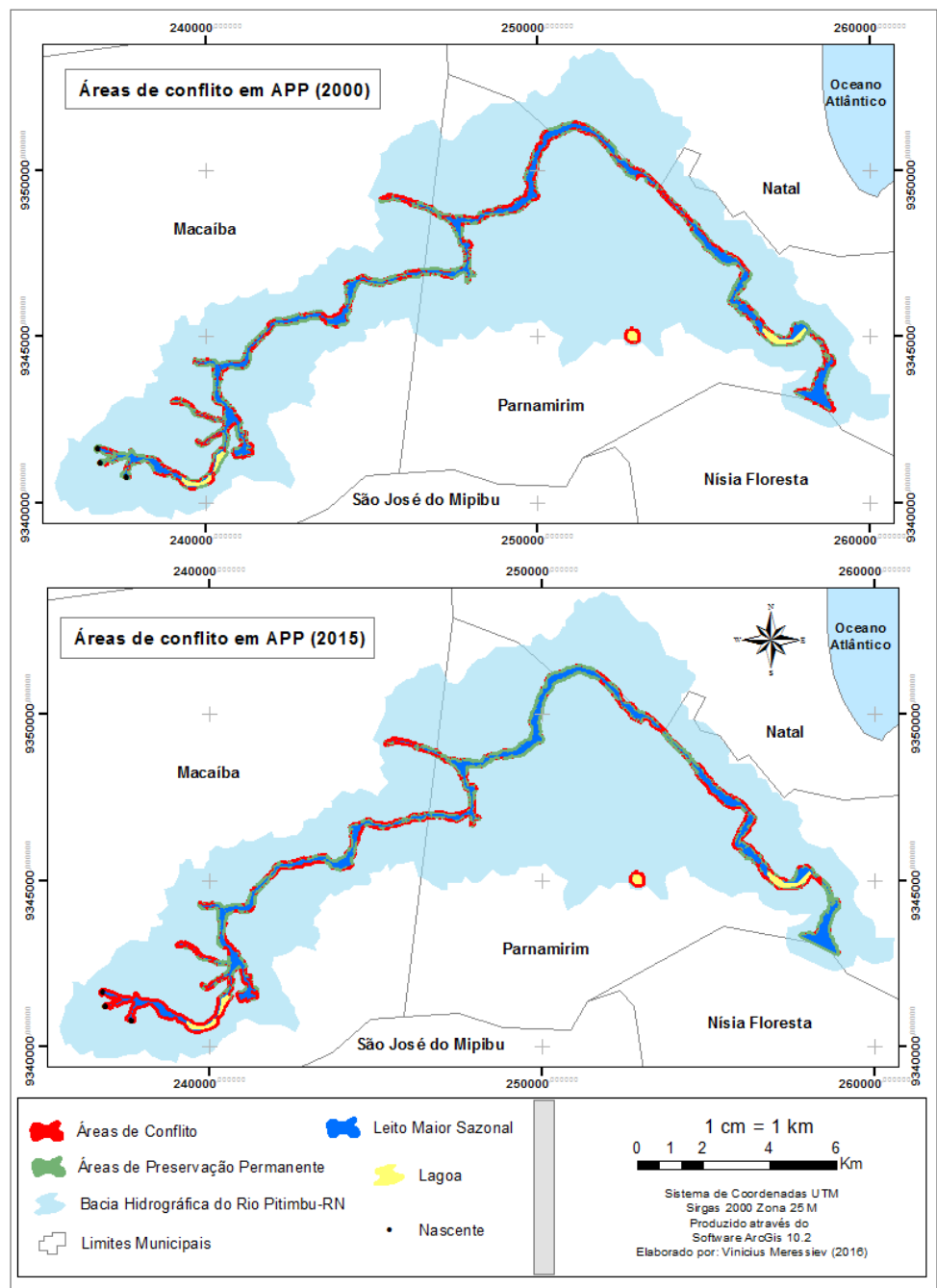

FIGURA 04 - ÁREAS DE CONFLITO ENTRE A COBERTURA DO SOLO E AS ÁREAS DE PRESERVAÇÃO PERMANENTE NA BACIA HIDROGRÁFICA DO RIO PITIMBU, RIO GRANDE DO NORTE (BRASIL) EM 2000 E 2015

FONTE: Os autores (2016).

\section{Análise e discussão dos resultados}

A partir da metodologia utilizada e apresentada, foi possível chegar aos resultados analisados e discutidos neste tópico. Neste contexto, ao analisar a Tabela 02, no ano de 2000 observa-se que a classe de cobertura do solo que predominava na bacia hidrográfica do Rio Pitimbu era a de vegetação, com 6.588,4 ha, ocupando cerca de 53,1\% da área total da bacia. Em segundo lugar de destaque, verificam-se as áreas antrópicas agrícolas, ocupando 24,6\% da bacia; em seguida, as áreas antrópicas não agrícolas $(15,2 \%)$; e por fim, o solo exposto $(7,1 \%)$.

Entretanto, esse quadro muda no ano de 2015 com a intensa expansão urbana, e consequente desmatamento, de modo que, nesse ano, as áreas antrópicas não agrícolas ocupam 5.235,5 hectares, representando cerca de $42,2 \%$ da área da bacia, enquanto que a classe de vegetação diminuiu 
consideravelmente se relacionada ao ano de 2000, ocupando apenas $29,6 \%$ da bacia. Por sua vez, as áreas antrópicas agrícolas e o solo exposto tiveram leve retração, de 1,3\% e 2,2\%, respectivamente.

Com isso, constata-se que durante o período pesquisado, a crescente expansão urbana dos municípios de Macaíba, Natal e Parnamirim pressionou os recursos naturais da bacia hidrográfica do Rio Pitimbu, com destaque para os impactos negativos sobre a vegetação, por meio do desmatamento. Com isso, os principais problemas ambientais relacionados à classe antrópica não agrícola nas áreas de preservação permanente na área supracitada são: desmatamento; lançamento de efluentes sanitários nos corpos hídricos; deposição irregular de resíduos sólidos; e impermeabilização do solo (VBA, 2005). Vale destacar também que a classe solo exposto se concentra principalmente no entorno das áreas antrópicas não agrícolas, onde o processo de urbanização tende a retirar a vegetação e impermeabilizar o solo. Por sua vez, a impermeabilização do solo pode causar um aumento do escoamento superficial, e, por consequência disso, elevação do processo de erosão laminar de solos mais frágeis, onde a vegetação foi retirada. Concomitantemente, poderá haver também um aumento no processo de sedimentação, nos pontos mais baixos do terreno, desse material erodido, podendo causar o assoreamento do Rio Pitimbu.

Por sua vez, a classe antrópica agrícola, nos dois anos pesquisados, ocupa uma área significativa na bacia hidrográfica do Pitimbu, concentrada principalmente na zona rural do município de Macaíba, e em uma pequena porção do município de Parnamirim. Essa classe caracteriza-se por agricultura tradicional com cultivo misto, de culturas cíclicas, de cultura permanente, pecuária de subsistência com plantio de capim e criação de gado, e agricultura modernizada com cultura permanente. Os principais problemas relacionados a essa classe, com relação às áreas de preservação permanente da bacia hidrográfica do Rio Pitimbu, são: desmatamento em nascente, uso de agrotóxicos próximo ao corpo hídrico e barramentos ilegais (VBA, 2005).

TABELA 02 - COBERTURA DO SOLO NA BACIA HIDROGRÁFICA DO PITIMBU RIO GRANDE DO NORTE (BRASIL), 2000 E 2015

\begin{tabular}{lcccc}
\hline \multicolumn{1}{c}{ Classes } & $\begin{array}{c}\text { Área 2000 } \\
\text { (ha) }\end{array}$ & $\begin{array}{c}\text { \% } \\
(\mathbf{2 0 0 0})\end{array}$ & $\begin{array}{c}\text { Área 2015 } \\
\text { (ha) }\end{array}$ & $\begin{array}{c}\text { \% } \\
\mathbf{( 2 0 1 5 )}\end{array}$ \\
\hline $\begin{array}{l}\text { Áreas antrópicas não } \\
\text { agrícolas }\end{array}$ & $1.885,0$ & 15,2 & $5.235,5$ & 42,2 \\
\hline Áreas antrópicas agrícolas & $3.049,0$ & 24,6 & $2.889,2$ & 23,3 \\
\hline Áreas de vegetação & $6.588,4$ & 53,1 & $3.667,6$ & 29,6 \\
\hline Solo exposto & 875,3 & 7,1 & 605,4 & 4,9 \\
\hline Total & $12.397,7$ & 100 & $12.397,7$ & 100 \\
\hline
\end{tabular}

FONTE: Os autores (2016). 
Podemos afirmar que a partir da análise da Tabela 03, no ano de 2000 a classe antrópica agrícola foi a que obteve uma maior taxa de conflito, ocupando 385 ha e representando cerca de $26 \%$ do espaço total das áreas de preservação permanente da bacia hidrográfica do Rio Pitimbu. Com pequena taxa de conflito nesse período, as áreas antrópicas não agrícolas invadiram apenas cerca de 5,6\% e o solo exposto 3,8\% das áreas de preservação permanente. Consequentemente, no período citado, o conjunto das classes de cobertura do solo da bacia hidrográfica do Rio Pitimbu ocuparam irregularmente $35,4 \%$ das áreas de preservação permanente, totalizando 524,7 ha de conflito.

Com relação ao ano de 2015, mesmo levando em consideração que a classe antrópica não agrícola representa, nesse ano, a maior parte da área total da bacia hidrográfica do Rio Pitimbu, podemos afirmar que é a classe antrópica agrícola que causa o maior conflito com as áreas de preservação permanente, ocupando cerca de 21,74\% destas, em uma área total de 322,20 ha. Em segundo lugar fica a classe antrópica não agrícola e, em seguida, ocupando um pequeno espaço, as áreas de solo exposto. Com isso, no ano em questão, as classes de cobertura do solo da bacia hidrográfica do Rio Pitimbu invadiram cerca de $42,5 \%$ do espaço destinado por lei para áreas de preservação permanente, ocupando irregularmente 630,3 ha, com aumento de 105,6 ha de conflito, em comparação ao ano 2000.

TABELA 03 - ÁREA DE CONFLITO EM ÁREAS DE PRESERVAÇÃO PERMANENTE POR CLASSE DE COBERTURA DO SOLO, NA BACIA HIDROGRÁFICA DO RIO PITIMBU, RIO GRANDE DO NORTE (BRASIL), EM 2000 E 2015

\begin{tabular}{|c|c|c|c|c|}
\hline Classes & $\begin{array}{c}\text { Área } \\
2000 \\
\text { (ha) }\end{array}$ & $\begin{array}{c}\% \\
2000\end{array}$ & $\begin{array}{c}\text { Área } \\
2015 \\
\text { (ha) }\end{array}$ & $\begin{array}{c}\% \\
2015\end{array}$ \\
\hline Áreas antrópicas agrícolas & 385,0 & 26,0 & 322,2 & 21,7 \\
\hline $\begin{array}{l}\text { Áreas antrópicas não } \\
\text { agrícolas }\end{array}$ & 83,4 & 5,6 & 279,0 & 18,8 \\
\hline Solo exposto & 56,3 & 3,8 & 29,1 & 2,0 \\
\hline Total & 524,7 & 35,4 & 630,3 & 42,5 \\
\hline
\end{tabular}

Esse dado é de extrema importância, uma vez que a partir dele é possível propor um indicador institucional de sustentabilidade, com base na relação percentual dos locais de conflito com o espaço total das áreas de preservação permanente, denominado aqui de taxa de conflito em áreas de APP. Esse deve ser considerado institucional, visto que cabe, principalmente, às instituições federais, estaduais ou municipais competentes garantir que a legislação que rege essas áreas seja cumprida a partir de ações de controle e de fiscalização. 
Dessa forma, o presente indicador deverá seguir a estrutura lógica representada pela Figura 05, em que o índice de sustentabilidade da bacia hidrográfica do Rio Pitimbu (ISBP) deverá ser o produto final, quando calculado a partir de diversas dimensões, entre elas a institucional; e estas formadas por diversos temas, entre eles o de controle institucional; e os diversos temas formados por múltiplos indicadores, como o de taxa de conflito em APP, aqui proposto.

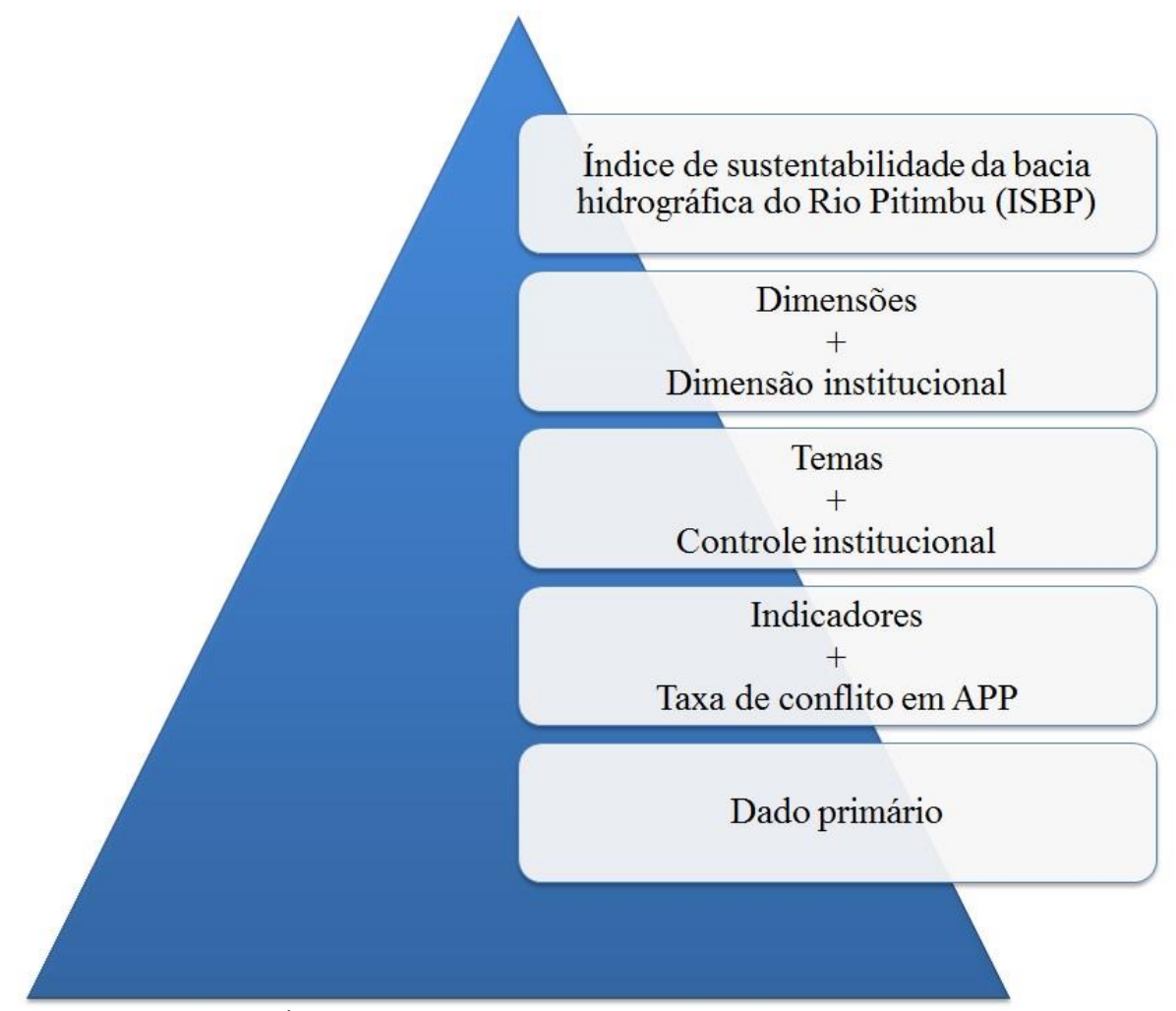

FIGURA 05 - ESTRUTURA LÓGICA NA QUAL SE INSERE O INDICADOR INSTITUCIONAL DE SUSTENTABILIDADE PROPOSTO E DENOMINADO TAXA DE CONFLITO EM ÁREA DE PRESERVAÇÃO PERMANENTE

FONTE: Adaptado pelos autores (2016) a partir da proposta de SICHE et al. (2007).

Levando em consideração a estrutura lógica apresentada, o indicador "Taxa de conflito em APP” deverá ser enquadrado de acordo com níveis de criticidade. Portanto, foi considerado que se a área de APP de uma bacia hidrográfica obteve uma área de conflito entre $0 \%$ e 4,99\%, será considerada como conflito nulo ou acrítico. Se as áreas de conflito variarem entre 5\% e 9,99\% serão consideradas como potencialmente acríticos. Porém, se essas áreas variarem entre 10\% e 19,99\%, serão consideradas como conflitos intermediários. Mas se as áreas de conflito estiverem entre $20 \%$ e $39,99 \%$ podem ser consideradas como conflitos potencialmente críticos. Por fim, se essas áreas de conflito forem iguais ou maiores do que 40\%, a área de APP deverá ser considerada conflito crítico, como segue na Tabela 06. 
TABELA 06 - CLASSIFICAÇÃO PROPOSTA PARA O INDICADOR TAXA DE CONFLITO EM ÁREA DE PRESERVAÇÃO PERMANENTE

\begin{tabular}{lc}
\hline \multicolumn{1}{c}{ Classificação } & Valor (\%) \\
\hline Conflito acrítico ou nulo & {$[0 ; 4,99]$} \\
\hline Conflito potencialmente acrítico & {$[5 ; 9,99]$} \\
\hline Conflito intermediário & {$[10 ; 19,99]$} \\
\hline Conflito potencialmente crítico & {$[20 ; 39,99]$} \\
\hline Conflito crítico & {$[40 ; 100]$} \\
\hline
\end{tabular}

FONTE: Os autores (2016).

Isso posto, a partir dos resultados encontrados e da proposição apresentada, o indicador "Taxa de conflito em APP", da bacia hidrográfica do Rio Pitimbu para o ano de 2000 é classificado como conflito potencialmente crítico, devido ao fato de $35,4 \%$ da sua área já ter sido invadida por atividades antrópicas, contrariando o estabelecido no Código Florestal ainda em vigor naquele ano, a Lei $\mathrm{n}^{\circ}$ 4.771, de 1965. Porém, para o ano de 2015, a criticidade de conflito aumentou e é classificada como conflito crítico, pois cerca de 42,5\% das áreas de APP, nesse ano, encontram-se ocupadas de forma irregular, segundo a Lei Estadual $n^{\circ} 8.426$, que dispõe sobre a faixa de proteção ambiental do Rio Pitimbu, em vigor desde 2003.

Desse modo, é importante destacar que a referida bacia hidrográfica se encontrava protegida legalmente durante todo o período pesquisado, através do antigo Código Florestal (Lei $\mathrm{n}^{\circ}$ 4.771, de 1965) com relação ao ano de 2000, e do Novo Código Florestal (Lei no 12.651, de 2012) e legislação estadual (Lei $n^{\circ} 8.426$, de 2003) no que concerne à análise do ano de 2015. Tal proteção legal envolve uma demanda da sociedade que se reflete em uma preocupação do poder público em preservar o recurso natural florestal e hídrico, presente de forma geral nas bacias hidrográficas, e em específico na bacia hidrográfica do Rio Pitimbu, tão importante para um desenvolvimento sustentável.

Porém, como podemos afirmar, com relação aos dados encontrados pela pesquisa, existe uma contradição, pois a sociedade ao mesmo tempo em que demanda uma política pública de preservação de recursos naturais a descumpre. Esse fato mostra o quão desigual a nossa sociedade é, em termos de consciência ambiental, e quanto o poder público é deficiente com relação a pôr em prática instrumentos de fiscalização e controle do uso do solo e, consequentemente, cumprimento da legislação. 


\section{Considerações finais}

A partir da metodologia empregada, assim como dos resultados apresentados, pode-se concluir que a utilização do indicador institucional de sustentabilidade, aqui denominado "Taxa de conflito em APP”, é viável para a detecção de degradação das áreas de preservação permanente, contribuindo para a gestão territorial e ambiental da área de estudo.

Vale ressaltar a importância do geoprocessamento de dados espaciais em um sistema de informação geográfica aplicado em estudos desse tipo, de modo que o produto cartográfico gerado pode ser utilizado pelos tomadores de decisão para o planejamento e direcionamento de ações com vistas à manutenção das áreas de preservação permanente do Rio Pitimbu, como por meio do monitoramento contínuo e ações de fiscalização in loco. Destaca-se também que esse indicador pode ser integrado a um conjunto de outros indicadores, nas dimensões ambiental, social, econômica e institucional, para mensurar e avaliar a sustentabilidade da bacia hidrográfica do Rio Pitimbu de uma forma mais abrangente.

Dessa forma, o indicador proposto por esta pesquisa, a partir da comparação de dois momentos históricos distintos, contribuiu para um diagnóstico que auxilia na avaliação dos processos que causaram a reestruturação do território nos anos analisados. Com isso, em termos comparativos nos dois instantes de tempo analisados, conclui-se que a bacia hidrográfica do Pitimbu vem indicando um desenvolvimento insustentável devido, principalmente, à influência causada pelas atividades antrópicas agrícolas anteriores a 2000, e no intervalo de 15 anos estudado aqui, pelas atividades antrópicas não agrícolas.

Portanto, podemos deduzir que a intensa e rápida expansão urbana dos municípios de Natal e Parnamirim, influenciada principalmente por programas de acesso à habitação popular como o Minha Casa Minha Vida, implementado pelo governo federal, e o próprio crescimento populacional, causaram um aumento significativo de áreas de conflitos entre a cobertura do solo e áreas de preservação permanente na bacia hidrográfica do Pitimbu.

Portanto, é significativo salientar a importância dos órgãos de controle e de fiscalização ambiental, assim como a conscientização dos demais atores sociais, produtores do espaço da bacia hidrográfica do Rio Pitimbu, quanto à preservação dessas áreas e ao cumprimento da lei.

\section{Referências}

BARBOSA, J. K. F. Conflito de uso da água e ocupação do solo da bacia hidrográfica do rio Pitimbu no município de Macaíba-RN. Natal: UFRN, 2006. 
BELLEN, H. M. V. Indicadores de sustentabilidade: uma análise comparativa. Rio de Janeiro: FGV, 2005.

BORGES, A. N. Implicações ambientais na bacia hidrográfica do rio Pitimbu (RN) decorrentes das diversas formas de uso e ocupação do solo. Natal: UFRN, 2002.

BRASIL. Indicadores de desenvolvimento sustentável: Brasil 2012. Rio de Janeiro: IBGE, 2012.

Lei $\mathbf{n}^{0}$ 12.651, de 25 de maio de 2012. Diário Oficial da República Federativa do Brasil, Poder Executivo, Brasília, DF, 28 mai. 2012. Secção 1, p. 16.

. Manual técnico de uso da terra. 3 ed. Rio de Janeiro: IBGE, 2013.

Resolução Conama no 04, de 18 de setembro de 1985. Diário Oficial da República Federativa do Brasil, Poder Executivo, Brasília, DF, 20 jan. 1986, p. 1095-1096.

BRITO, D. M. C.; BASTOS, C. M. C. B.; FARIAS, R. T. S.; BRITO, D. M.; DIAS, G. A. C. Conflitos socioambientais no século XXI. PRACS, Macapá, n. 4, p. 51-58, dez. 2011.

COSTA, S. M. D. Alteração da cobertura vegetal natural da microbacia do rio Pitimbu-RN devido à ocupação antrópica. Natal: UFRN, 1995.

CRISTOFOLLETI, A. Geomorfologia. São Paulo: EDUSP, 1974.

GUERRA, A. J. T. Geomorfologia urbana. Rio de Janeiro: Bertrand Brasil, 2011.

GUIMARÃES, R. P.; FEICHAS, S. A. Q. Desafios na construção de indicadores de sustentabilidade. Ambiente e Sociedades, Campinas, v. 12, n. 2, p. 307-323, jul./dez. 2009.

ISAIAS, F. B. A sustentabilidade da água: proposta de um índice de sustentabilidade de bacias hidrográficas. Brasília: UNB, 2008.

KURY, A. G. Minidicionário Gama Kury da língua portuguesa. São Paulo: FTD, 2002.

LIBISZEWSKI, S. What is an environmental conflict? Zurich: Center for Security Studies, 1992.

LOPES, F. W. A.; DUTRA, G. C.; PEREIRA, J. A. A.; CARVALHO, L. M. T. Avaliação da influência de áreas de solo exposto sobre a qualidade das águas do Ribeirão de Carrancas - MG. In: XIII Simpósio Brasileiro de Sensoriamento Remoto, 2007, Florianópolis. Anais... Florianópolis: INPE, 21-26 abril 2007, p. 3421-3428.

MELO, P. T. N. B. Indicadores da dimensão institucional do desenvolvimento sustentável e os objetivos da Rio +20. Editora Unijuí, São Geraldo, v. 11, n. 23, maio/ago. 2013.

OLIVEIRA, A. S. Uso e ocupação do solo e a concentração de metais pesados no sedimento e na água: bacia do rio Pitimbu. Natal: UFRN, 2012.

PEREIRA, M. S.; WITKOSKI, A. C. Construção da paisagem, espaço e lugar na várzea do rio Solimões-Amazonas. Novos Cadernos NAEA, Belém, v. 15, n. 1, p. 273-290, jun. 2012. 
RIBEIRO, R. F. Introdução à questão metodológica. In: DIEGUES, A. C. S. Conflitos sociais e meio ambiente: desafios políticos e conceituais. Rio de Janeiro: Ibase, 1995.

RIO GRANDE DO NORTE. Lei no 8.426, de 14 de novembro de 2003. Diário Oficial do Estado do Rio Grande do Norte, Poder Executivo, Natal, RN, 14 nov. 2003.

SARADÓN, J. S. El desarrollo y uso de indicadores para evaluar la sustentabilidade de los agroecossistemas. Agroecología: el caminho hacia uma agricultura sustentable - E.C.A., 2013.

SASAHARA, C. Sustentabilidade: a perda do caráter de mudança estrutural do conceito. Piracicaba: USP, 2009.

SCHÃFFER, W. B.; ROSA, M. R.; AQUINO, L. C. S. MEDEIROS, J. D. Áreas de preservação permanente e unidades de conservação \& áreas de risco: o que uma coisa tem a ver com a outra? Relatório de Inspeção da área atingida pela tragédia das chuvas na Região Serrana do Rio de Janeiro. Brasília: MMM, 2011.

SENA, D. S. Avaliação da qualidade da água do rio Pitimbu. Natal: UFRN, 2008.

SEPÚLVEDA, S. S. Biograma: metodología para estimar el nível de desarrollo sostenible de territórios. San José: IICA, 2008.

SICHE, R.; AGOSTINHO, F.; ORTEGA, E.; ROMEIRO, A. Índices versus indicadores: precisões conceituais na discussão da sustentabilidade de países. Ambiente \& Sociedade, Campinas, v. X, n. 2, p. 137-148, jul./dez. 2007.

TUCCI, C. E. M.; MENDES, C. A. Avaliação ambiental integrada de bacia hidrográfica. Brasília: MMA, 2006.

TURNER, M. D. Political ecology and the moral dimensions of "resource conflicts": the case of farmer-herder conflicts in the Sahel. Political Geography, v. 23, p. 863-889, 2004.

VAZ, L.; ORLANDO, P. H. K. Importância das matas ciliares para manutenção da qualidade das águas de nascentes: diagnóstico do ribeirão vai-vem de Ipameri - GO In: XXI ECONTRO NACIONAL DE GEOGRAFIA AGRÁRIA, 2012, Uberlândia. Anais... Uberlândia: UFU, 2012, p. 1-20.

VBA CONSULTORES S/C LTDA \& TECNOSOLO. Elaboração do Plano de Gestão Integrada da Bacia do rio Pitimbu: Versão Final dos Relatórios. Natal: Secretaria de Estado dos Recursos Hídricos. CD. 2005.

YASSUDA, E. R. Gestão de recursos hídricos: fundamentos e aspectos institucionais. Administração Pública, Rio de Janeiro, v. 27, n. 2, p. 5-18, abr./jun. 1993.

Artigo recebido em 18/01/2017. Aceito para publicação em 24/05/2017. 